\title{
Developmental timing of Drosophila pachea pupae is robust to temperature changes
}

running title: Temperature and development in D. pachea

Bénédicte M. Lefèvre ${ }^{\mathrm{a}, \mathrm{b}^{*}}$ and Michael Lang ${ }^{\mathrm{a}^{*}}$

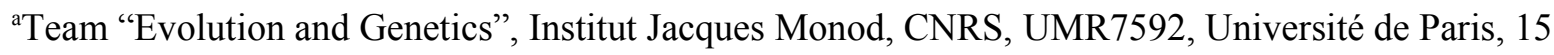 rue Hélène Brion, 75013 Paris

\begin{abstract}
${ }^{\text {b} C u r r e n t ~ a d d r e s s: ~ T e a m ~ " S t e m ~ C e l l s ~ a n d ~ T i s s u e ~ H o m e o s t a s i s ", ~ I n s t i t u t ~ C u r i e, ~ C N R S, ~ U M R 3215, ~}$ INSERM U934, PSL Research University, 26 rue d’Ulm, 75248 Paris Cedex 05
\end{abstract}

\section{Co-authors details}

Bénédicte M. Lefèvre

Team "Evolution and Genetics", Institut Jacques Monod, CNRS, UMR7592, Université de Paris, 15 rue Hélène Brion, 75013 Paris; current address: Team "Stem Cells and Tissue Homeostasis", Institut Curie, CNRS, UMR 3215, INSERM U934, PSL Research University, 26 rue d'Ulm, 75248 Paris Cedex 05; benedictelefevre@gmail.com; ORCID ID: 0000-0002-1958-2886.

\section{Michael Lang}

Team "Evolution and Genetics", Institut Jacques Monod, CNRS, UMR 7592, Université de Paris, 15 rue Hélène Brion, 75013 Paris; michael.lang@ijm.fr; ORCID ID: 0000-0002-2297-5680.

\section{Author contributions}

$\mathrm{BL}$ and $\mathrm{ML}$ designed the experiments. BL generated and analysed the data. BL and ML wrote the manuscript. All authors read and approved the final manuscript.

\section{Conflict of interest}

The authors have no conflict of interest to declare. 


\section{Abstract}

37 wide range of poikiloterm animals that do not regulate their body temperature. However,

38 exceptions exist, especially in species that live in environments with high temperature

39 extremes or oscillations. Drosophila pachea is endemic to the Sonoran desert in Mexico, in

40 which temperatures and temperature variations are extreme. We wondered if the

41 developmental timing in $D$. pachea may be sensitive to differing rearing temperatures or if it

42 remains constant. We determined the overall timing of the Drosophila pachea life-cycle at

$4325^{\circ} \mathrm{C}$ and $29^{\circ} \mathrm{C}$. The duration of pupal development was similar at both temperatures

44 although the relative progress differed at particular stages. Thus, D. pachea may have

45 evolved mechanisms to buffer temperature influence on developmental speed, potentially to

46 ensure proper development and individual's fitness in desert climate conditions.

47

\section{Keywords}

49 Drosophila pachea, pupal development, temperature, heterochrony 


\section{$51 \quad$ Highlights}

52

53

54

55

56

- In poikilotherms, developmental speed usually increases with rearing temperature

61

- Global pupal development of D. pachea is similar at two different rearing temperatures

- Discrete temperature dependent timing differences at specific pupal stages

- D. pachea development is longer compared to other Drosophila species

- Temperature-buffering mechanisms may have evolved to ensure a proper development 


\section{Introduction}

Poikilotherms animals do not regulate their body temperature contrary to

66 homeotherms (Precht et al., 1973) and are sensitive to environmental temperature.

67 Environmental temperature in turn affects their metabolism (Hazel and Prosser, 1974). In particular, it seems widespread that developmental speed increases with rearing temperature in poikilothermic species (Abril et al., 2010; Asano and Cassill, 2012; Hrs-

70 Brenko et al., 1977; Ikemoto, 2005; Manoj Nair and Appukuttan, 2003; Nishizaki et al., 2015;

71 Pechenik et al., 1990; Porter, 1988; Sharpe and DeMichele, 1977; Vélez and Epifanio,

72 1981), including various Drosophila species (David and Clavel, 1966; James and Partridge,

73 1995; Kuntz and Eisen, 2014; Powsner, 1935). This phenomenon is proposed to be due to

74 thermodynamics of enzymes responsible for biochemical reactions underlying developmental processes (Ikemoto, 2005; Schoolfield et al., 1981; Sharpe and DeMichele, 1977). Thermal-stress can accelerate development and has been shown to result in an increase of developmental instability (Kristensen et al., 2003; Nishizaki et al., 2015; Polak and Tomkins, 2013), measured as deviations of an individual's character from the average phenotype in the population under the same conditions (Palmer, 1994; Zakharov, 1992).

80 This may result in a decreased individual's survival and reproductive fitness. In contrast, a

81 slow development may potentially lead to an increased risk of predation at vulnerable

82 stages, such as immobile pupae in holometabolous insects (Ballman et al., 2017; Borne et

83 al., 2021; Hennessey, 1997; Thomas, 1993; Urbaneja et al., 2006). Furthermore, a variable

84 timing of development among individuals of a same species might induce intraspecific competition (Amarasekare and Coutinho, 2014; Frogner, 1980) as individuals developing faster may reproduce sooner and for a longer period compared to those developing more slowly. Different mechanisms have been found to regulate developmental timing. The socalled "heterochronic genes" were originally discovered in Caenorhabditis elegans

89 (Rhabditida: Rhabditidae) (Ambros and Horvitz, 1984) and have been found to control the 90 developmental timing. These genes are conserved in a wide range of animals species, such as Drosophila melanogaster (Diptera : Drosophilidae) (Caygill and Johnston, 2008) or Danio rerio (Cypriniformes: Cyprinidae) (Ouchi et al., 2014) and play a role in the regulation of the timing of developmental processes. Hormones are also known to be important regulators of developmental timing. In D. melanogaster, each of the developmental transitions are regulated by ecdysone pulses, and premature transition from larva to pupa with respect to food conditions or starvation is prevented by juvenile hormone (Riddiford, 1994; Riddiford and Ashburner, 1991). Thus, developmental timing might be regulated to reach an optimal duration with respect to outer environmental factors. 
More than 1500 described species of the genus Drosophila (Bächli et al., 2021; O'Grady and DeSalle, 2018) occupy a wide range of habitats with various climatic conditions (Markow and O'Grady, 2008). A dozen of species have been reported to be cosmopolitan species (Markow and O'Grady, 2008, 2005), such as Drosophila melanogaster (David and Capy, 1988; Li and Stephan, 2006) that potentially dispersed with humans from Africa around the globe (Mansourian et al., 2018). These species may be generalists but were also found to be locally adapted to diverse environments (Kapun et al., 2020; Markow and O'Grady, 2008). In contrast, the vast majority of species are restricted to certain continental ranges or are endemic to a specific geographic region that encompasses a unique habitat with specific food and climate conditions (Markow and O'Grady, 2008, 2005). Because of their inability to disperse outside their habitat, these endemic species may have evolved temperature-buffering mechanisms to ensure a constant developmental timing under variable temperature conditions.

\section{Drosophila pachea (Diptera : Drosophilidae) is endemic to the Sonoran desert in} Mexico and is an obligate specialist on decayed parts, or rot-pockets, of its single host plant, the Senita cactus (Lophocereus schottii) (Gibbs et al., 2003; Heed and Kircher, 1965; Lang et al., 2012; Markow and O'Grady, 2005). The micro-climate of the rot-pockets encompasses important changes of temperature all along the year, with a recorded maximum variation from $5^{\circ} \mathrm{C}$ to $42^{\circ} \mathrm{C}$ within $24 \mathrm{~h}$ (Gibbs et al., 2003). Living in an environment with large daily and annual temperature changes may require a certain temperature robustness with respect to developmental processes in poikiloterm species. We wondered if the developmental timing in $D$. pachea may be sensitive to differing rearing temperatures. To test this, we first determined the overall timing of the Drosophila pachea life-cycle. Then, we focussed on pupal development at two different rearing temperatures to investigate differences in the pupal timing. Finally, we compared these durations across closely related sister species Drosophila acanthoptera (Diptera : Drosophilidae) and Drosophila nannoptera (Diptera : Drosophilidae) to investigate potential species-specific developmental timing differences.

\section{Materials and methods}

\subsection{Drosophila stock maintenance}

Drosophila stocks were retrieved from the San Diego Drosophila Species Stock Center (now The National Drosophila Species Stock Center, College of Agriculture and Life Science, Cornell University, USA). The D. pachea stock 15090-1698.01 was established in 1997 from individuals caught in Arizona, USA. The D. nannoptera stocks 15090-1692.00 and 
15090-1693.12 were established in 1992 from individuals caught in Oaxaca, Mexico. The $D$. acanthoptera stock 15090-1693.00 was established in 1976 from individuals caught in Oaxaca, Mexico (UCSC Drosophila species stock center San Diego, now The National Drosophila Species stock center, Cornell University). These stocks have been kept in good conditions at $25^{\circ} \mathrm{C}$ in our laboratory since 2012.

Flies were maintained in transparent plastic vials $(25 \times 95 \mathrm{~mm}$, Dutscher) containing about $10 \mathrm{~mL}$ of standard Drosophila medium. This medium was composed of $66.6 \mathrm{~g} / \mathrm{L}$ of cornmeal, $60 \mathrm{~g} / \mathrm{L}$ of brewer's yeast, $8.6 \mathrm{~g} / \mathrm{L}$ of agar, $5 \mathrm{~g} / \mathrm{L}$ of methyl-4-hydroxybenzoate and $2.5 \% \mathrm{v} / \mathrm{v}$ ethanol (standard food). We added $40 \mu \mathrm{L}$ of $5 \mathrm{mg} / \mathrm{mL}$ of 7 -dehydrocholesterol (7DHC) (Sigma, reference 30800-5G-F) dissolved in ethanol into the food for $D$. pachea, as this species need this sterol for proper development (Heed and Kircher, 1965; Lang et al., 2012; Warren et al., 2001) (standard D. pachea food). As a pupariation support, a piece of paper sheet $\left(1 \mathrm{~cm} \times 4 \mathrm{~cm}\right.$, BenchGuard) was added to each vial. Stocks were kept at $25^{\circ} \mathrm{C}$ or $29^{\circ} \mathrm{C}$ at a $12 \mathrm{~h}$ light: $12 \mathrm{~h}$ dark photoperiodic cycle with a $30 \mathrm{~min}$ transition between light $(1080 \mathrm{Im})$ and dark $(0 \mathrm{~lm})$.

\subsection{Cohort synchronisation of $D$. pachea embryos and time-lapse recording of} embryonic development

For collection of cohorts of synchronised embryos, about 250-500 adult flies were transferred into a $9 \times 6 \mathrm{~cm}$ plastic cylinder, closed by a net on the top and by a $5.5 \mathrm{~cm}$ diameter petri-dish lid at the bottom. The petri-dish contained grape juice agar $(24.0 \mathrm{~g} / \mathrm{L}$ agar, $26.4 \mathrm{~g} / \mathrm{L}$ saccharose, $20 \%$ grape juice, $50 \%$ distilled water, $12 \%$ Tegosept $[1.1 \mathrm{~g} / \mathrm{mL}$ in ethanol] (Dutscher), 4\% 7-DHC (Sigma)) and 50-200 $\mu \mathrm{L}$ fresh baker's yeast as food source and egg laying substrate on top. These plates are named hereinafter "food plates". Female flies were let to lay eggs on the food plates for $1 \mathrm{~h}$, thus embryos had a maximum age difference of $60 \mathrm{~min}$. Then, eggs were retrieved from food plates by filtering the yeast paste through a $100 \mu \mathrm{m}$ nylon mesh (BS, Falcon 352360).

For time-lapse imaging the chorion of embryos was removed by a $90 \mathrm{sec}$ incubation of the embryo-containing filter in $1.3 \%$ bleach (BEC Javel) under constant agitation until about half of the embryos were floating at the surface of the bleach bath. Embryos were extensively rinsed with tap water for at least $30 \mathrm{sec}$. Dechorionated embryos were then gently glued on a cover slip (ThermoFisher) coated with Tesa glue. For coating, $50 \mathrm{~cm}$ TESA tape was transferred into $25 \mathrm{~mL}$-heptane (Merck) and glue was let to dissolve overnight at 
166

167

168

169

170

171

172

173

174

175

176

177

178

179

180

181

182

183

184

185

186

187

188

189

190

191

192

193

194

195

196

197

198

room temperature. A total of $15 \mu \mathrm{L}$ of dissolved glues was finally pipetted onto a cover slip to form a $5 \times 20 \mathrm{~mm}$ rectangular stripe and n-heptane was let to evaporate. Embryos were covered with $40 \mu \mathrm{L}$ of Voltalef $10 \mathrm{~S}$ halocarbon oil (VWR) to avoid desiccation. Live-imaging was immediately launched inside a temperature and humidity controlled chamber at $25^{\circ} \mathrm{C} \pm$ $0.1^{\circ} \mathrm{C}$ and $80 \% \pm 1 \%$ humidity (Lang and Orgogozo, 2012; Lefèvre et al., 2021; Rhebergen et al., 2016). Time-lapse acquisition was performed at an acquisition rate of 1 picture every $7.5 \mathrm{sec}$ using a digital camera (Conrad 9-Megapixel USB digital microscope camera) and Cheese software, version 3.18.1, on a computer with an ubuntu 16.04 linux operating system. Movies were assembled with avconv (libav-tools).

Out of 28 embryos monitored, 12 (43\%) pursued their development until hatching while the others did not develop at all. Such mortality has been reported previously (Jefferson, 1977; Pitnick, 1993) but potentially also dependent on the above-mentioned bleach treatment. The embryos that died during the experiment were excluded from analysis. Furthermore, the duration of hatching, which is the last stage of embryonic development, has been shown to be more variable in comparison to the other embryonic stages in various Drosophila species (Kuntz and Eisen, 2014). We thus measured both the total embryonic duration, from collection up to larva hatching and the embryonic duration up to the trachea gaz filling stage, which precedes the hatching stage.

\subsection{Cohort synchronisation of larvae, dissection and imaging of larval mouth hooks}

In order to collect cohorts of larvae at a synchronous developmental stage, we first collected embryos from a $2 \mathrm{~h}$ egg laying interval (see above) that were placed on a food plate together with fresh yeast. Freshly hatched larvae were retrieved from the yeast paste with fine forceps (Dumont \#5, Fine Science Tool) or by filtering the yeast through a nylon mesh (see above). Larvae were transferred into vials containing standard Drosophila pachea food and were examined once a day until all larvae had turned into pupae.

For imaging of the larval teeth, entire larvae were mounted in $20 \mu \mathrm{L}$ dimethylhydantoin formaldehyde (DMHF) medium (Entomopraxis) beneath a cover slip $(0.17 \mathrm{~mm} \pm$ $0.01 \mathrm{~mm}$ thick, ThermoScientific), which was gently pressed against the microscope slide (ThermoScientific) to orient larval teeth in a flat, lateral orientation to the microscope objective. Larval teeth were imaged at 100 or 400 fold magnification in bright field illumination (Strasburger, 1935) using the microscope IX83 (Olympus). The instar stage of each dissected individual was determined based on tooth morphology (Strasburger, 1935) 
199

200

201

202

203

204

205

206

207

208

209

210

211

212

213

214

215

216

217

218

219

220

221

222

223

224

225

226

227

228

229

230

231

(Figure S1).

\subsection{Measurement of the duration of puparium formation in $D$. pachea}

The precise duration of puparium formation was characterized by monitoring nine $D$. pachea pupariating larvae by time-lapse imaging. Larvae at the third instar stage and third instar wandering stage were collected from the $D$. pachea stock and were transferred into fresh $D$. pachea standard medium, inside a $5 \mathrm{~cm}$ diameter petri-dish and a piece of $1 \mathrm{~cm} \times 4$ $\mathrm{cm}$ paper sheet (BenchGuard). The dish was then placed into the temperature and humidity controlled chamber at $25^{\circ} \mathrm{C} \pm 0.1^{\circ} \mathrm{C}$ and $80 \% \pm 1 \%$ humidity, as previously described. Timelapse acquisition was performed for about $72 \mathrm{~h}$ as previously described for embryonic timing characterization. The duration of the white puparium stage was measured from the moment when the larva had everted the anterior spiracles and had stopped moving until the moment when the pupal case had turned brown.

\subsection{Characterization of developmental timing in pupae}

The developmental duration of $D$. pachea, $D$. nannoptera and $D$. acanthoptera was examined by observation of pupae at different time points after puparium formation (APF).

Synchronised pupae were obtained from each species by collecting so-called "white pupae" that had just formed the puparium (Dataset S1). Specimens were collected with a wet brush directly from stock vials. Individuals of the same cohort were placed onto moist Kimtech tissue (Kimberly-Clark) inside a $5 \mathrm{~cm}$ diameter petri dish. Petri dishes with pupae were kept at $25^{\circ} \mathrm{C}$ or $29^{\circ} \mathrm{C}$ inside plastic boxes, which also contained wet tissue paper. A group of pupae resulting from a single collection event was considered as a synchronised cohort. Developmental progress of synchronised cohorts (Table 1) was examined at various time points by visual examination of the pupae using a stereomicroscope VisiScope SZB 200 (VWR) (Dataset S2). Developmental stages were assigned according to morphological markers defined for D. melanogaster by Bainbridge and Bownes (1981) (Table 2). The markers used to characterize stages 8 to 12 (eye, wing or body pigmentation, Table 2) were not convenient for the characterization by direct observation of $D$. acanthoptera pupae as these flies develop black eyes, as opposed to most other Drosophila species that have red eyes. In addition, $D$. acanthoptera is generally less pigmented compared to $D$. pachea and D. nannoptera (Pitnick and Heed, 1994) and pigmentation changes were not easily detectable through the pupal case. Therefore, we additionally carried out time-lapse imaging 
of one cohort with five $D$. acanthoptera pupae to investigate the developmental durations of stages 8-12. The anterior part of the pupal case was removed, letting the head and the anterior part of the thorax visible. Image acquisition was done at $25^{\circ} \mathrm{C} \pm 0.1^{\circ} \mathrm{C}$ and $80 \% \pm$ $1 \%$ humidity, as previously described. Time-lapse acquisition was performed as previously described and recorded with the VLC media player, version 3.0 at an acquisition rate of 1 picture every 13:02 min. Two pupae died during acquisition and were excluded from the analysis.

\subsection{Data analysis}

Data was manually entered into spreadsheets (Datasets S1 and S2) and analysis was performed in R version 3.6 (R Core Team, 2014). Ages expressed in hours after pupa formation were automatically calculated with respect to the time point of white pupa collection.

\section{Results}

3.1. D. pachea embryonic and larval development at $25^{\circ} \mathrm{C}$ last for about $33 \mathrm{~h}$ and 216 h, respectively

We characterized the duration of embryonic and larval development in $D$. pachea at $25^{\circ} \mathrm{C}$. The average duration of the total embryonic development in $D$. pachea at $25^{\circ} \mathrm{C}$, until hatching of the larva was 32 h 48 min \pm 1 h 13 min (mean \pm standard deviation ; $n=12$ ) (Figure 1). Embryonic development up to the trachea gas filling stage (see Material and Methods for details) was estimated to be $26 \mathrm{~h} 48 \mathrm{~min} \pm 1 \mathrm{~h} 13$ min (mean \pm standard deviation ; $n=12$ ). These durations appeared to be longer in $D$. pachea compared to those reported for various other Drosophila species, such as Drosophila melanogaster, Drosophila simulans, Drosophila sechellia, Drosophila yakuba, Drosophila pseudoobscura, Drosophila mojavensis (Figure 2) (David and Clavel, 1966; Kuntz and Eisen, 2014; Powsner, 1935).

The total duration of $D$. pachea larval development on standard $D$. pachea food at $25^{\circ} \mathrm{C}$ was 9 days (approximately $216 \mathrm{~h}$ ). The duration of the first and second instar larva were about 2 days each and the third instar stage lasted for about 5 days (Figure 1). In $D$. melanogaster, the total duration of the larval stage was about 5 days for larvae reared on optimal food at $25^{\circ} \mathrm{C}$, the first and second instars lasting for 1 day each, and the third instar for three days, according to Strasburger, (1935). The larval development of $D$. pachea 
appeared thus to be longer compared to those of $D$. melanogaster at $25^{\circ} \mathrm{C}$.

\subsection{The timing of the pupal development is conserved up to the pharate adult stage} estimated to last for $102 \mathrm{~min} \pm 41 \mathrm{~min}$ (mean \pm standard deviation) $(\mathrm{n}=9)$ at $25^{\circ} \mathrm{C}$. This duration has to be considered as the remaining variation of developmental progress between examined individual pupae in later timing analyses (see Materials and Methods). This duration was similar to previously reported durations for $D$. melanogaster white pupae of 80$120 \mathrm{~min}$, at $25^{\circ} \mathrm{C}$ (Bainbridge and Bownes, 1981).

At $25^{\circ} \mathrm{C}$, the pharate adult stage (stage 7 , Table 2 ) was observed about $55 \mathrm{~h}$ after puparium formation and emergence of adults between 115 - $145 \mathrm{~h}$ after puparium formation (Figures 2A). This timing was similar to those of $D$. acanthoptera and $D$. nannoptera (Figure 3B). The developmental duration from puparium formation to pharate adult (stages 1 to 7 , from $0 \mathrm{~h} \mathrm{APF}$ to about $55 \mathrm{~h}$ APF) was also similar to those reported for $D$. melanogaster and D. guttifera (Figure 3B) (Bainbridge and Bownes, 1981; Fukutomi et al., 2017). However, at later pupal development durations of stages were prolonged in $D$. pachea, $D$. nannoptera and $D$. acanthoptera compared to $D$. melanogaster and $D$. guttifera. within $D$. pachea, $D$. nannoptera and $D$. acanthoptera. $D$. pachea adults emerge between 115 - 144 h APF, D. nannoptera adults between 112 - $140 \mathrm{~h}$ APF and D. acanthoptera adults between $102 \mathrm{~h}-142 \mathrm{~h}$ APF. The variance of this stage was significantly different between the three species (Levene's test: $F=3.4414$, $D f=2, p=0.03847$ ), the stage 15 being longer in $D$. acanthoptera compared to $D$. pachea and $D$. nannoptera (Figure 3B).

\subsection{The duration of pupal development in $D$. pachea is not affected by two different} rearing temperatures

The duration of larval development appears to be sensitive to various environmental factors, such as diet (Matzkin et al., 2011), crowding, or access to food (Vijendravarma et al., 2013). Since pupal development is apparently less affected by such factors, we focussed on the pupal stage to investigate the effect of the rearing temperature on timing of 
reared at temperature below $25^{\circ} \mathrm{C}$ is prolonged which favors the accumulation of bacterial infections in the food and decreased survival of the flies. At rearing temperature above $30^{\circ} \mathrm{C}$, the food dries out rapidly which causes problems for larvae to feed. We thus chose to compare the development of $D$. pachea at $25^{\circ} \mathrm{C}$ and $29^{\circ} \mathrm{C}$ as these two temperatures allow proper survival.

At $29^{\circ} \mathrm{C}, D$. pachea pupae reached the pharate adult stage in less than $55 \mathrm{~h}$, similar to their development at $25^{\circ} \mathrm{C}$ (Figures $2 \mathrm{~A}, 2 \mathrm{C}$ and 2D). However, pupal development is accelerated at $29^{\circ} \mathrm{C}$ between stages 8 and 13 (beginning of eye pigmentation until the end of body and wing pigmentation) compared to development at $25^{\circ} \mathrm{C}$ (Figures $2 \mathrm{~A}, 2 \mathrm{C}$ and $2 \mathrm{D}$ ). However, stages 14 and 15 required more time at $29^{\circ} \mathrm{C}$ and resulted in a similar overall developmental duration of about $100-145 \mathrm{~h}$ at $29^{\circ} \mathrm{C}$ compared to $115-145 \mathrm{~h}$ at $25^{\circ} \mathrm{C}$ (Figure 3). In comparison, the overall pupal development of $D$. melanogaster lasts about 80 $\mathrm{h}$ at $29^{\circ} \mathrm{C}$ and $100 \mathrm{~h}$ at $25^{\circ} \mathrm{C}$ (Powsner, 1935). Thus, in D. pachea the rearing temperature influences the relative progress of pupal development at particular stages. However, the overall duration appears to be similar at both temperatures.

\section{Discussion}

\subsection{A possible temperature-buffering mechanism during pupal development}

The trend of a decrease of developmental duration when rearing temperature increases was not observed in $D$. pachea, overall pupal development duration being similar at $25^{\circ} \mathrm{C}$ and $29^{\circ} \mathrm{C}$. On the contrary, the duration of the overall pupal development decreases with increasing rearing temperature in D. melanogaster (Ashburner and Thompson Jr, 1978; Powsner, 1935). In addition, temperature fluctuations during pupal development of $D$. melanogaster are known to either increase or decrease developmental speed (Ludwig and Cable, 1933; Petavy et al., 2001). In this species, the first $24 \mathrm{~h}$ of pupal development are more sensitive to temperature changes compared to the rest of the pupal stage (Ludwig and Cable, 1933; Petavy et al., 2001). While D. melanogaster is a cosmopolitan species that lives in a wide climate range (David and Capy, 1988), D. pachea is a desert species endemic of the Sonora (Heed and Kircher, 1965; Markow and O'Grady, 2005). The mean daily variations of temperature of this habitat are $18^{\circ} \mathrm{C}-42^{\circ} \mathrm{C}$ in spring/summer and $6^{\circ} \mathrm{C}-32^{\circ} \mathrm{C}$ in fall/winter (Gibbs et al., 2003). D. pachea is found in the wild throughout the year but undergoes a strong population decline during August, when the seasonal temperatures are highest (Breitmeyer and Markow, 1998). However, adult $D$. pachea are particularly resistant to high-temperatures and survive up to $44^{\circ} \mathrm{C}$, while most other Drosophila species revealed 
331 a decreasing survival already at $38^{\circ} \mathrm{C}$ (Stratman and Markow, 1998). Thus, this species may

332 have developed some heat resistance mechanisms or a certain tolerance to temperature

333 variations that would buffer temperature changes on the developmental progress. This

334 buffering effect could potentially be important for proper development since heat stress has been reported to increase developmental instability in various species (Kristensen et al., 2020; Breuker and Brakefield, 2003; Carvalho et al., 2017; Enriquez et al., 2018). and could perhaps ensure the emergence of the adult fly at a particular moment of the day, such as dawn or dusk, when the environmental temperature might be most suitable for the freshly emerged individual. In the last pupal stage that corresponds to the adult emergence, we observed timing variation between individuals in $D$. pachea (up to $30 \mathrm{~h}$ between individuals). This variation could potentially depend on individual differences or on environmental factors that we could not control, such as the light/dark illumination cycle at the moment of adult emergence. Such circadian regulation of adult emergence has been observed in various Drosophila species (Ashburner et al., 2004; Mark et al., 2021; Powsner, 1935; Soto et al., 2018). However, the important variation in the last pupal stage is also found among individuals of the same cohort (Datasets S1 and S2). Future monitoring of the emergence of adults from various cohorts collected at different moments of the day will be necessary to test this hypothesis. Future investigations will be needed to further characterize the potential temperature buffering effect during $D$. pachea development and to test the influence of the circadian rhythm in this species. In addition, we must further assess temperature dependent pupal development in a wider range of species that live in distinct climate habitats.

\subsection{Conservation of the overall developmental progress during early pupal stages}

The detailed analysis of the timing of pupal stages revealed that the first stages 1 to D. guttifera (Fukutomi et al., 2017), and the three closely related species $D$. pachea, $D$. acanthoptera and $D$. nannoptera. Later on, pupal development appears to be more variable between species. This may indicate the existence of some developmental constraints, which are limitations of phenotypic variability due to inherent properties of the developmental system (Smith et al., 1985; Wagner, 2014). Such constraints probably act on outgrowth of 
366

367

368

369

370

371

372

373

374

375

376

377

378

379

380

381

382

383

384

385

386

387

388

389

390

391

392

larval stages but undergo extensive tissue growth during pupal development up to the pharate adult stage. Thereafter, the timing of development seems to be less constrained and interspecific variations were observed. At least a part of the variation in the pupal developmental timing could be attributed to the developmental marker used. As the coloration markers are qualitative, it is hard to define precise limits of each stage (ie. eyes turn progressively from yellow to red). A solution might be to identify a combination of multiple markers for each stage or to establish gene expression markers that are known to account for specific developmental processes, as it has been recently done for eye development (Escobedo et al., 2021) or male genitalia development (Vincent et al., 2019).

\subsection{Longer embryonic and larval development durations in $D$. pachea compared to}

\section{other Drosophila species}

The embryonic developmental duration at $25^{\circ} \mathrm{C}$ has been investigated in 11 drosophila species other than D. pachea (David and Clavel, 1966; Kuntz and Eisen, 2014; Powsner, 1935) (Figure 2) and ranged from $16 \mathrm{~h}$ in $D$. sechellia to $25 \mathrm{~h}$ in D. virilis (Kuntz and Eisen, 2014) (Figure 2), which are shorter compared to embryonic development of $D$. pachea at the same temperature. Interspecific variation in the duration of embryonic development might rely on genetic factors, as closely related species tend to have similar embryonic developmental durations compared to those of distantly related ones (Figure 2).

Larval development is longer in $D$. pachea compared to those in $D$. melanogaster (Bakker, 1959; Strasburger, 1935). However, the duration of this developmental stage has been shown to be highly variable compared to the other life stages. In particular it has been shown that larvae are very sensitive to food composition and to crowding that affect food quality and food access (Matzkin et al., 2011; Vijendravarma et al., 2013). Food quality and food access in turn prolong the larval developmental duration (Matzkin et al., 2011). This effect of food on developmental duration might also probably affect embryonic and pupal stages indirectly due to nutrient contribution from the adult and larval stages.

The slower development observed in $D$. pachea raised in the lab might be due to variations in the ecdysone metabolism. In insects, ecdysone is first provided to the embryo as maternal contribution and then directly produced by the individual (Lafont et al., 2012). However, in $D$. pachea the first metabolic step of the ecdysone biosynthesis is different compared to other insect species, the conversion of cholesterol into 7-dehydrocholesterol being abolished (Lang et al., 2012). Instead, D. pachea metabolizes sterols produced by the Senita cactus on which they feed, such as lathosterol, and potentially campestenol and 
400 schottenol (Heed and Kircher, 1965), into steroid hormones differing in their side residues

401 (Lang et al., 2012). Therefore, in the wild, D. pachea may produce different variants of

402 ecdysone that may also differently affect developmental timing compared to the lab

403 conditions that only provide the single ecdysone precursor 7-dehydrocholesterol. Thus, it

404 would be interesting to compare developmental durations of $D$. pachea fed with standard $D$.

405 pachea food used in the lab or with their natural host plant, the Senita cactus. In addition,

406 further investigations would be needed to elucidate how temperature modulates these

407 mechanisms.

408

409

410

411

412

413

414

415

416

417

418

419

420

\subsection{Conclusion}

We investigated the effect of temperature on developmental speed in $D$. pachea, a desert species. We characterized the timing of the life-cycle in this species and observed prolonged developmental durations compared to other Drosophila species. The global developmental duration at pupal stage is similar at two different rearing temperatures although stage specific timing differences were observed. These observations indicate that D. pachea might potentially have evolved mechanisms to buffer the effect of temperature on developmental speed. Such mechanisms might be of importance to preserve the fitness of individuals exposed to extreme temperatures and important temperature variations during their development.

\section{Acknowledgements}

We thank all team members of the Evolution and Genetics team, including Jean David, for stimulating and constructive discussions. We thank Virginie Courtier for comments on the manuscript and for covering experimental costs.

\section{Funding sources}

BL was supported by a pre-doctoral fellowship Sorbonne Paris Cité of the Université Paris 7 Denis Diderot and by a fellowship from the Labex "Who am I?" ["Initiatives d'excellence", Idex ANR-18-IDEX-0001, ANR-11-LABX-0071]. This work was further supported by the CNRS, by a grant of the European Research Council under the European Community's Seventh Framework Program [FP7/2007-2013 Grant Agreement no. 337579] given to Virginie Courtier-Orgogozo and by a grant of the Agence Nationale pour la recherche [ANR-20-CE13-0006] given to ML.

\section{References}


Abrieux, A., Xue, Y., Cai, Y., Lewald, K.M., Nguyen, H.N., Zhang, Y., Chiu, J.C., 2020. EYES ABSENT and TIMELESS integrate photoperiodic and temperature cues to regulate seasonal physiology in Drosophila. Proc. Natl. Acad. Sci. 117, 15293-15304. https://doi.org/10.1073/pnas.2004262117

Abril, S., Oliveras, J., Gómez, C., 2010. Effect of temperature on the development and survival of the Argentine ant, Linepithema humile. J. Insect Sci. 10. https://doi.org/10.1673/031.010.9701

Amarasekare, P., Coutinho, R.M., 2014. Effects of temperature on intraspecific competition in ectotherms. Am. Nat. 184, E50-E65.

Ambros, V., Horvitz, H.R., 1984. Heterochronic mutants of the nematode Caenorhabditis elegans. Science 226, 409-416.

Asano, E., Cassill, D.L., 2012. Modeling temperature-mediated fluctuation in colony size in the fire ant, Solenopsis invicta. J. Theor. Biol. 305, 70-77. https://doi.org/10.1016/j.jtbi.2012.03.011

Ashburner, M., Golic, K.G., Hawley, R.S., 2004. Drosophila: a laboratory handbook. Cold spring harbor laboratory press.

Bächli, G., Bernhard, U., Godknecht, A., 2021. TaxoDros [data base].

Bainbridge, S.P., Bownes, M., 1981. Staging the metamorphosis of Drosophila melanogaster. Development 66, 57-80.

Bakker, K., 1959. Feeding period, growth, and pupation in larvae ofDrosophila melanogaster. Entomol. Exp. Appl. 2, 171-186.

Ballman, E.S., Collins, J.A., Drummond, F.A., 2017. Pupation behavior and predation on Drosophila suzukii (Diptera: Drosophilidae) pupae in Maine wild blueberry fields. J. Econ. Entomol. 110, 2308-2317.

Borne, F., Prigent, S.R., Molet, M., Courtier-Orgogozo, V., 2021. Drosophila glue protects from predation. Proc. R. Soc. B 288, 20210088.

Breitmeyer, C.M., Markow, T.A., 1998. Resource availability and population size in cactophilic Drosophila. Funct. Ecol. 12, 14-21. https://doi.org/10.1046/j.13652435.1998.00152.x

Breuker, C.J., Brakefield, P.M., 2003. Heat shock in the developmentally sensitive period of butterfly eyespots fails to increase fluctuating asymmetry. Evol. Dev. 5, 231-239.

Carvalho, G.B., Drago, I., Hoxha, S., Yamada, R., Mahneva, O., Bruce, K.D., Obando, A.S., Conti, B., Ja, W.W., 2017. The 4E-BP growth pathway regulates the effect of ambient temperature on Drosophila metabolism and lifespan. Proc. Natl. Acad. Sci. 114, 9737-9742. https://doi.org/10.1073/pnas.1618994114

Caygill, E.E., Johnston, L.A., 2008. Temporal regulation of metamorphic processes in Drosophila by the let-7 and miR-125 heterochronic microRNAs. Curr. Biol. 18, 943950.

David, J., Clavel, F., 1966. Essai de définition d'une température optimale pour le développement de la Drosophile. Comptes-Rendus Hebd. Séances Académie Sci. 262, 2159.

David, J.R., Capy, P., 1988. Genetic variation of Drosophila melanogaster natural populations. Trends Genet. 4, 106-111.

Enriquez, T., Renault, D., Charrier, M., Colinet, H., 2018. Cold Acclimation Favors Metabolic Stability in Drosophila suzukii. Front. Physiol. 0. https://doi.org/10.3389/fphys.2018.01506

Escobedo, S.E., Shah, A., Easton, A.N., Hall, H., Weake, V.M., 2021. Characterizing a gene expression toolkit for eye- and photoreceptor-specific expression in Drosophila. Fly (Austin) 15, 73-88. https://doi.org/10.1080/19336934.2021.1915683

Frogner, K.J., 1980. Variable Developmental Period: Intraspecific Competition Models with Conditional Age-Specific Maturity and Mortality Schedules. Ecology 61, 1099-1106.

Fukutomi, Y., Matsumoto, K., Agata, K., Funayama, N., Koshikawa, S., 2017. Pupal development and pigmentation process of a polka-dotted fruit fly, Drosophila guttifera (Insecta, Diptera). Dev. Genes Evol. 1-10.

Gibbs, A.G., Perkins, M.C., Markow, T.A., 2003. No place to hide: microclimates of Sonoran 
Desert Drosophila. J. Therm. Biol. 28, 353-362.

Hazel, J.R., Prosser, C.L., 1974. Molecular mechanisms of temperature compensation in poikilotherms. Physiol. Rev. 54, 620-677.

Heed, W.B., Kircher, H.W., 1965. Unique sterol in the ecology and nutrition of Drosophila pachea. Science 149, 758-761.

Hennessey, M.K., 1997. Predation on wandering larvae and pupae of Caribbean fruit fly(Diptera: Tephritidae) in guava and carambola grove soils. J. Agric. Entomol. 14, 129-138.

Hrs-Brenko, M., Claus, C., Bubic, S., 1977. Synergistic effects of lead, salinity and temperature on embryonic development of the mussel Mytilus galloprovincialis. Mar. Biol. 44, 109-115.

Ikemoto, T., 2005. Intrinsic optimum temperature for development of insects and mites. Environ. Entomol. 34, 1377-1387.

James, A.C., Partridge, L., 1995. Thermal evolution of rate of larval development in Drosophila melanogaster in laboratory and field populations. J. Evol. Biol. 8, 315330.

Jefferson, M.C., 1977. BREEDING BIOLOGY OF DROSOPHILA PACHEA AND ITS RELATIVES. The University of Arizona.

Kapun, M., Barrón, M.G., Staubach, F., Obbard, D.J., Wiberg, R.A.W., Vieira, J., Goubert, C., Rota-Stabelli, O., Kankare, M., Bogaerts-Márquez, M., Haudry, A., Waidele, L., Kozeretska, I., Pasyukova, E.G., Loeschcke, V., Pascual, M., Vieira, C.P., Serga, S., Montchamp-Moreau, C., Abbott, J., Gibert, P., Porcelli, D., Posnien, N., SánchezGracia, A., Grath, S., Sucena, É., Bergland, A.O., Guerreiro, M.P.G., Onder, B.S., Argyridou, E., Guio, L., Schou, M.F., Deplancke, B., Vieira, C., Ritchie, M.G., Zwaan, B.J., Tauber, E., Orengo, D.J., Puerma, E., Aguadé, M., Schmidt, P., Parsch, J., Betancourt, A.J., Flatt, T., González, J., 2020. Genomic Analysis of European Drosophila melanogaster Populations Reveals Longitudinal Structure, ContinentWide Selection, and Previously Unknown DNA Viruses. Mol. Biol. Evol. 37, 26612678. https://doi.org/10.1093/molbev/msaa120

Kristensen, T.N., Pertoldi, * Cino, Andersen, D.H., Loeschcke, V., 2003. The use of fluctuating asymmetry and phenotypic variability as indicators of developmental instability: a test of a new method employing clonal organisms and high temperature stress. Evol. Ecol. Res. 5, 53-68.

Kuntz, S.G., Eisen, M.B., 2014. Drosophila Embryogenesis Scales Uniformly across Temperature in Developmentally Diverse Species. PLoS Genet. 10, e1004293. https://doi.org/10.1371/journal.pgen.1004293

Lafont, R., Dauphin-Villemant, C., Warren, J.T., Rees, H., 2012. 4 - Ecdysteroid Chemistry and Biochemistry, in: Gilbert, L.I. (Ed.), Insect Endocrinology. Academic Press, San Diego, pp. 106-176. https://doi.org/10.1016/B978-0-12-384749-2.10004-4

Lang, M., Murat, S., Clark, A.G., Gouppil, G., Blais, C., Matzkin, L.M., Guittard, É., Yoshiyama-Yanagawa, T., Kataoka, H., Niwa, R., Lafont, R., Dauphin-Villemant, C., Orgogozo, V., 2012. Mutations in the neverland Gene Turned Drosophila pachea into an Obligate Specialist Species. Science 337, 1658-1661. https://doi.org/10.1126/science.1224829

Lang, M., Orgogozo, V., 2012. Distinct copulation positions in Drosophila pachea males with symmetric or asymmetric external genitalia. Contrib. Zool. 81.

Lefèvre, B.M., Catté, D., Courtier-Orgogozo, V., Lang, M., 2021. Male genital lobe morphology affects the chance to copulate in Drosophila pachea. BMC Ecol. Evol. 21, 1-13.

Li, H., Stephan, W., 2006. Inferring the Demographic History and Rate of Adaptive Substitution in Drosophila. PLOS Genet. 2, e166. https://doi.org/10.1371/journal.pgen.0020166

Ludwig, D., Cable, R.M., 1933. The effect of alternating temperatures on the pupal development of Drosophila melanogaster Meigen. Physiol. Zool. 6, 493-508.

Manoj Nair, R., Appukuttan, K.K., 2003. Effect of temperature on the development, growth, 
survival and settlement of green mussel Perna viridis (Linnaeus, 1758). Aquac. Res. 34, 1037-1045.

Mansourian, S., Enjin, A., Jirle, E.V., Ramesh, V., Rehermann, G., Becher, P.G., Pool, J.E., Stensmyr, M.C., 2018. Wild African Drosophila melanogaster Are Seasonal Specialists on Marula Fruit. Curr. Biol. 28, 3960-3968.e3. https://doi.org/10.1016/j.cub.2018.10.033

Mark, B., Bustos-González, L., Cascallares, G., Conejera, F., Ewer, J., 2021. The circadian clock gates Drosophila adult emergence by controlling the timecourse of metamorphosis. Proc. Natl. Acad. Sci. 118.

Markow, T.A., O'Grady, P., 2008. Reproductive ecology of Drosophila. Funct. Ecol. 22, 747759. https://doi.org/10.1111/j.1365-2435.2008.01457.x

Markow, T.A., O'Grady, P., 2005. Drosophila: a guide to species identification and use. Elsevier.

Matzkin, L.M., Johnson, S., Paight, C., Bozinovic, G., Markow, T.A., 2011. Dietary Protein and Sugar Differentially Affect Development and Metabolic Pools in Ecologically Diverse Drosophila. J. Nutr. 141, 1127-1133. https://doi.org/10.3945/jn.111.138438

Nishizaki, M.T., Barron, S., Carew, E., 2015. Thermal stress increases fluctuating asymmetry in marine mussels: environmental variation and developmental instability. Ecosphere 6, art85. https://doi.org/10.1890/ES14-00399.1

O'Grady, P.M., DeSalle, R., 2018. Phylogeny of the genus Drosophila. Genetics 209, 1-25.

Ouchi, Y., Yamamoto, J., Iwamoto, T., 2014. The heterochronic genes lin-28a and lin-28b play an essential and evolutionarily conserved role in early zebrafish development. PloS One 9, e88086.

Palmer, A.R., 1994. Fluctuating asymmetry analyses: a primer, in: Developmental Instability: Its Origins and Evolutionary Implications. Springer, pp. 335-364.

Pechenik, J.A., Eyster, L.S., Widdows, J., Bayne, B.L., 1990. The influence of food concentration and temperature on growth and morphological differentiation of blue mussel Mytilus edulis L. larvae. J. Exp. Mar. Biol. Ecol. 136, 47-64.

Petavy, G., David, J.R., Gibert, P., Moreteau, B., 2001. Viability and rate of development at different temperatures in Drosophila: a comparison of constant and alternating thermal regimes. J. Therm. Biol. 26, 29-39. https://doi.org/10.1016/S03064565(00)00022-X

Pitnick, S., 1993. Operational sex ratios and sperm limitation in populations of Drosophila pachea. Behav. Ecol. Sociobiol. 33. https://doi.org/10.1007/BF00170253

Pitnick, S., Heed, W.B., 1994. New species of cactus-breeding Drosophila (Diptera: Drosophilidae) in the nannoptera species group. Ann. Entomol. Soc. Am. 87, 307310.

Polak, M., Tomkins, J.L., 2013. Developmental selection against developmental instability: a direct demonstration. Biol. Lett. 9, 20121081. https://doi.org/10.1098/rsbl.2012.1081

Porter, S.D., 1988. Impact of temperature on colony growth and developmental rates of the ant, Solenopsis invicta. J. Insect Physiol. 34, 1127-1133. https://doi.org/10.1016/0022-1910(88)90215-6

Powsner, L., 1935. The effects of temperature on the durations of the developmental stages of Drosophila melanogaster. Physiol. Zool. 8, 474-520.

Precht, H., Christophersen, J., Hensel, H., Larcher, W., 1973. Homeothermy and Poikilothermy, in: Temperature and Life. Springer, pp. 505-508.

Rhebergen, F.T., Courtier-Orgogozo, V., Dumont, J., Schilthuizen, M., Lang, M., 2016. Drosophila pachea asymmetric lobes are part of a grasping device and stabilize onesided mating. BMC Evol. Biol. 16, 176.

Riddiford, L.M., 1994. Cellular and molecular actions of juvenile hormone I. General considerations and premetamorphic actions. Adv. Insect Physiol. 24, 213-274.

Riddiford, L.M., Ashburner, M., 1991. Effects of juvenile hormone mimics on larval development and metamorphosis of Drosophila melanogaster. Gen. Comp. Endocrinol. 82, 172-183.

Schoolfield, R.M., Sharpe, P.J.H., Magnuson, C.E., 1981. Non-linear regression of biological 
temperature-dependent rate models based on absolute reaction-rate theory. J. Theor. Biol. 88, 719-731.

Sharpe, P.J., DeMichele, D.W., 1977. Reaction kinetics of poikilotherm development. J. Theor. Biol. 64, 649-670.

Smith, J.M., Burian, R., Kauffman, S., Alberch, P., Campbell, J., Goodwin, B., Lande, R., Raup, D., Wolpert, L., 1985. Developmental constraints and evolution: a perspective from the Mountain Lake conference on development and evolution. Q. Rev. Biol. 60, 265-287.

Soto, E.M., Padró, J., Carmona, P.M., Tuero, D.T., Carreira, V.P., Soto, I.M., 2018. Pupal emergence pattern in cactophilic Drosophila and the effect of host plants. Insect Sci. 25, 1108-1118. https://doi.org/10.1111/1744-7917.12484

Strasburger, E.H., 1935. Drosophila melanogaster meig. Springer.

Stratman, R., Markow, T.A., 1998. Resistance to thermal stress in desert Drosophila. Funct. Ecol. 12, 965-970.

Team, R.C., 2014. R: A language and environment for statistical computing. R Foundation for Statistical Computing, Vienna, Austria. 2013.

Thomas, D.B., 1993. Survivorship of the Pupal Stages of the Mexican Fruit Fly Anastrepha ludens (Loew) (Diptera: Tephritidae) in an Agricultural and a Nonagricultural Situation. J. Entomol. Sci. 28, 350-362. https://doi.org/10.18474/0749-8004-28.4.350

Urbaneja, A., Marí, F.G., Tortosa, D., Navarro, C., Vanaclocha, P., Bargues, L., Castañera, P., 2006. Influence of Ground Predators on the Survival of the Mediterranean Fruit Fly Pupae, Ceratitis capitata, in Spanish Citrus Orchards. Biocontrol 51, 611-626. https://doi.org/10.1007/s10526-005-2938-6

Vélez, A., Epifanio, C.E., 1981. Effects of temperature and ration on gametogenesis and growth in the tropical mussel Perna perna (L.). Aquaculture 22, 21-26.

Vijendravarma, R.K., Narasimha, S., Kawecki, T.J., 2013. Predatory cannibalism in Drosophila melanogaster larvae. Nat. Commun. 4, 1789. https://doi.org/10.1038/ncomms 2744

Vincent, B.J., Rice, G.R., Wong, G.M., Glassford, W.J., Downs, K.I., Shastay, J.L., CharlesObi, K., Natarajan, M., Gogol, M., Zeitlinger, J., 2019. An atlas of transcription factors expressed in male pupal terminalia of Drosophila melanogaster. G3 Genes Genomes Genet. 9, 3961-3972.

Wagner, G.P., 2014. Homology, genes, and evolutionary innovation. princeton university press.

Warren, J.T., Wismar, J., Subrahmanyam, B., Gilbert, L.I., 2001. Woc (without children) gene control of ecdysone biosynthesis in Drosophila melanogaster. Mol. Cell. Endocrinol. 181, 1-14.

Zakharov, V., M., 1992. Population phenogenetics: Analysis of developmental stability in natural populations. Acta Zool Fenn 191. 


\section{Tables}

638 Table 1: Total numbers of pupae and synchronised cohorts used in for pupal timing 639 characterization

\begin{tabular}{|l|l|l|l|}
\hline Species & Temperature $\left({ }^{\circ} \mathbf{C}\right)$ & $\begin{array}{l}\text { Total number of } \\
\text { pupae }\end{array}$ & $\begin{array}{l}\text { Total number of } \\
\text { synchronised cohorts }\end{array}$ \\
\hline D. pachea & 25 & 76 & 11 \\
\hline D. pachea & 29 & 42 & 5 \\
\hline D. nannoptera & 25 & 40 & 7 \\
\hline D. acanthoptera & 25 & 61 & 15 \\
\hline
\end{tabular}

641 Table 2: Summary of morphological markers used to stage pupae, according to

\section{Bainbridges and Bownes (1981)}

\begin{tabular}{|l|l|}
\hline $\begin{array}{l}\text { Pupal } \\
\text { stage }\end{array}$ & Description \\
\hline 1 & Pupariation: extremity of trachea are everted, pupa does not move anymore. \\
\hline 2 & Clear, white pupa. \\
\hline 3 & Light pigmentation, dorsal trachea still visible. \\
\hline 4 & Bubbles appea, dorsal trachea is not visible anymore, light pigmentation of the body. \\
\hline 5 & Cranial extremity is retracted, distal extremity of wings appeared. \\
\hline 6 & Yellow body is visible. \\
\hline 7 & Pharate adult, eyes are not yet pigmented. \\
\hline 8 & Eye discs become a bit yellower compared to the rest of the body. \\
\hline 9 & Orange eyes, transparent wings are visible. \\
\hline 10 & Deep red eyes. \\
\hline 11 & Bristles are visible on the thorax. \\
\hline 12 & Wings are clear grey, clear pigmentation of the body. \\
\hline 13 & Wings are completely black, grey pigmentation appears on the body. \\
\hline 14 & Meconium appeared under the form of a dark spot visible through the abdomen. \\
\hline 15 & Eclosion of the adult. \\
\hline
\end{tabular}


644

645

646

647

648

649

650

651

652

653

654

655

656

657

658

659

660

661

662

663

664

665

666

667

668

669

670

671

672

673

674

675

676

677

678

679

680

\section{Figures}

Figure 1: Timing of the embryonic and larval stages in $D$. pachea at $25^{\circ} \mathrm{C}$.

Embryo duration represents the time from egg laying to the hatching of the larva, based on time-lapse imaging. Larval stages were determined based on mouth hook morphology of dissected larvae from synchronised cohorts, according to Strasburger (1935). Numbers correspond to the number of individuals observed at each stage.

Figure 2: Durations of the embryonic development in various Drosophila species at 25 ${ }^{\circ} \mathrm{C}$.

The duration of total embryonic development of $D$. pachea (grey) was established based on time-lapse imaging. The data for the species other than $D$. pachea were extracted from: blue: Kuntz and Eisen, 2014 (duration up to the trachea filling stage, at $25^{\circ} \mathrm{C}$ ), yellow: David and Clavel, 1966 (total embryonic development, at $25^{\circ} \mathrm{C}$ ) and green: Powsner, 1935 (total embryonic development, at $25^{\circ} \mathrm{C}$ ). The data used to establish the cladogram was extracted from Yassin (2013) and Lang et al. (2014).

\section{Figure 3: Progress of pupal development in $D$. pachea, $D$. nannoptera, $D$.} acanthoptera, D. guttifera and D. melanogaster at $25^{\circ} \mathrm{C}$ and $29^{\circ} \mathrm{C}$.

A: Synchronised cohorts of $D$. pachea pupae at $25^{\circ} \mathrm{C}$ observed at various time points. The light blue boxes indicate the period of each stage. Grey dots indicate single observations. For each stage, the first number corresponds to the number of pupae observed at that stage, and the second to the number of cohorts from which they originate. B: Comparison of pupal development at $25^{\circ} \mathrm{C}$ in $D$. pachea (blue), $D$. acanthoptera (green) and $D$. nannoptera (yellow) based on observations of synchronized cohorts. The stages 8 to 12 were determined in $D$. acanthoptera by time-lapse imaging of developing pupae, after removal of the anterior part of the pupal case (dotted lines). Data of $D$. melanogaster (pink) and $D$. guttifera (purple) were retrieved from Bainbridge and Bownes (1981) and Fukutomi et al. (2017), respectively. C: Synchronised cohorts of $D$. pachea pupae at $29^{\circ} \mathrm{C}$ observed at various time points. The dark blue boxes correspond to the duration of each stage, the grey dots to single observations, and the first and second numbers are the number of observed pupae in each stage and number of cohorts from which they originate. D: Combined observation of developmental progress in $D$. pachea at $25^{\circ} \mathrm{C}$ (light blue) and $29^{\circ} \mathrm{C}$ (dark blue). 


\section{Supplementary data}

683 Figure S1: Mouth hook morphology at the three different larval instar.

684 Larval mouth hook from A: first, B: second and C: third larval instar in Drosophila pachea.

685 The scale bar is $10 \mu \mathrm{m}$.

686

Dataset S1: Pupae cohorts for developmental timing characterization

688

Dataset S2: Row data of the observations of pupal development in $D$. pachea at $25^{\circ} \mathrm{C}$

690 and $29^{\circ} \mathrm{C}$, and in $D$. acanthoptera and $D$. nannotpera at $25^{\circ} \mathrm{C}$

691 


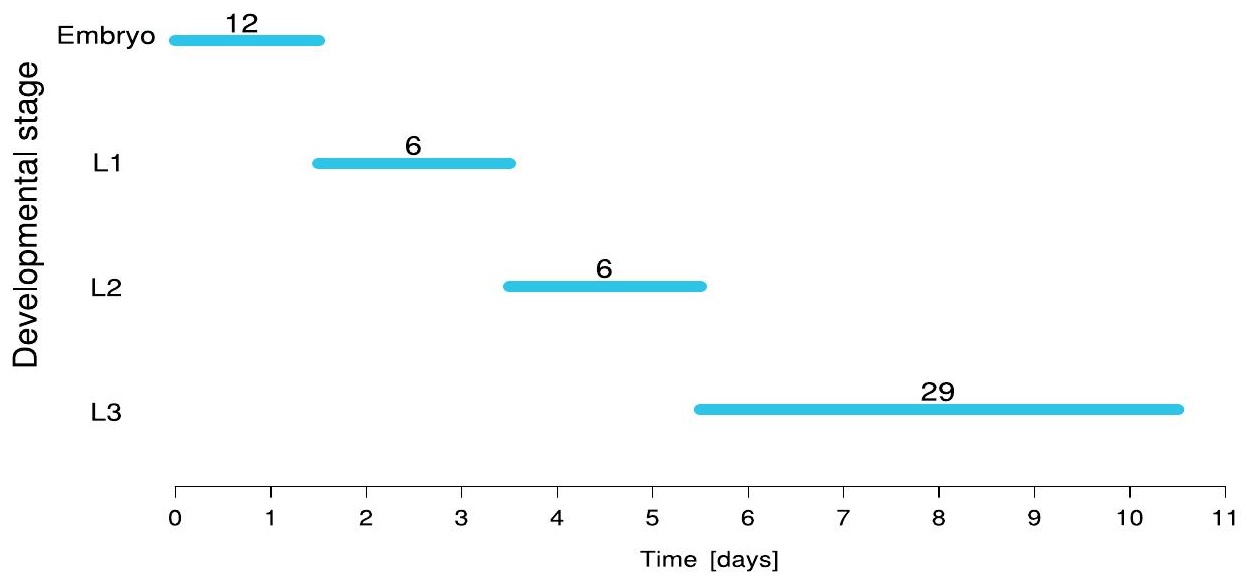



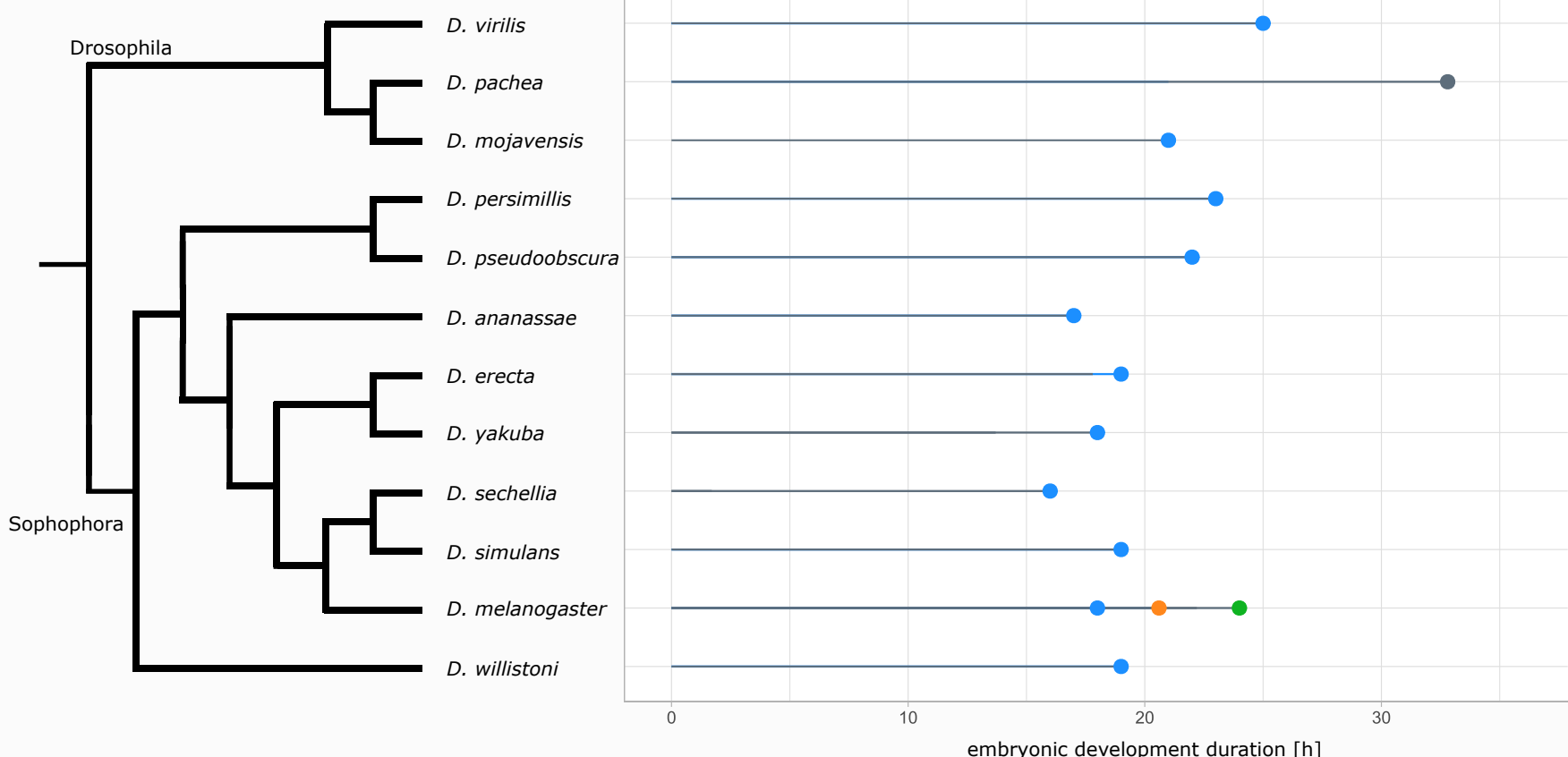

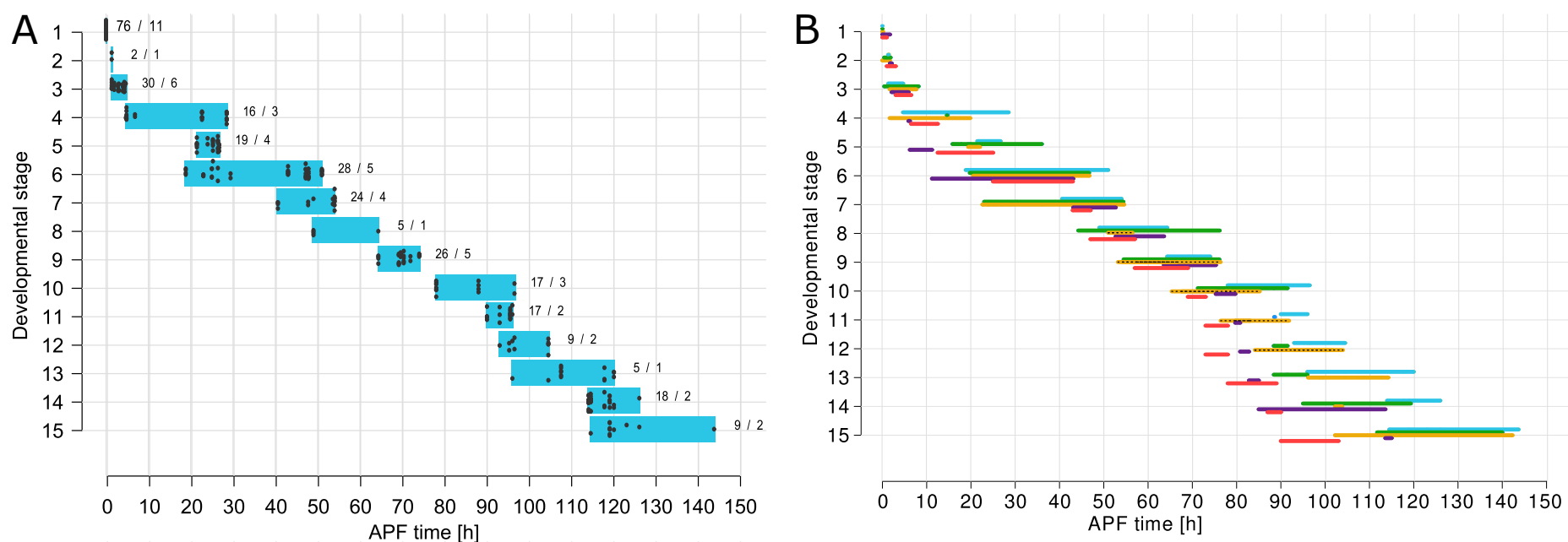

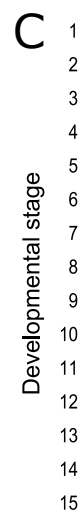

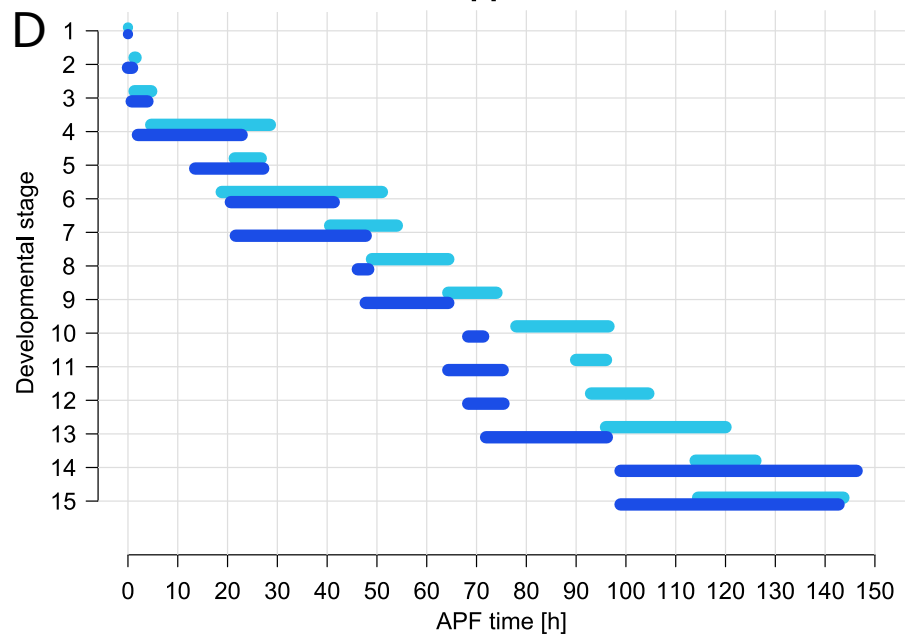

